\title{
Geospatial Technologies in Waste Management: A Case Study of Rivers State Waste Management Agency (RIWAMA)
}

\author{
Robinson Tombari Sibe \\ Rivers State University, \\ Port Harcourt \\ Rivers State, Nigeria
}

\author{
Ian Abraham Gobo \\ Rivers State Waste Management Agency, \\ Port Harcourt, \\ Rivers State, Nigeria
}

\begin{abstract}
Waste Management can be quite challenging, especially in the developing world. The challenge becomes even more complex with the growing population. City planners and decision makers are turning to technology to improve the efficiency of the waste management process. Geospatial technologies have offered a range of solutions, which have been deployed with success in waste management. This paper highlights the challenges of waste management in Port Harcourt, Nigeria, and how the Rivers State Waste Management Agency (RIWAMA) deployed the use of GIS in solving most of the challenges of identification, planning, evacuation, and transportation of wastes within the Port Harcourt metropolis. This paper looked at how this solution was deployed to solve key challenges as well as stimulate citizen participation in the waste management process. The paper concludes with a set of recommendations for expanding the potentials of its application.
\end{abstract}

Keywords: Web GIS; Mobile GIS; Waste Management; Waste Management Application; GIS; Geospatial Application; RIWAMA; RIWAMA Geospatial Application; Open-Source GIS.

\section{INTRODUCTION}

The City of Port Harcourt is one of the most populous cities in Nigeria. As the hub of the hydrocarbon industry in Nigeria, the city has witnessed exponential growth in population in the last few decades. From a 1991 census figure of 440,399 the city grew to $1,005,904$ in 2006, (Nna \& Pabon, 2012). The colonial city founded a little over a hundred years ago has also witnessed exponential expansion in size, reflective of the demographic push. From a size of 15.54 sq.km in 1914 when Nigeria was amalgamated, the city expanded to an area of 360 sq.km by the 1980's (Wizor, 2014). With this exponential growth in population, comes the challenge of waste management. This is one of the key challenges of urbanization (Elenwo, 2015), and Port Harcourt has had her fair share of the challenge. City planners continue to turn to technology to solve this problem, and this paper will $\mathrm{x}$-ray one of such solutions - Geographic Information System (GIS).

\section{GEOSPATIAL TECHNOLOGIES}

Geospatial technologies are tools used for acquiring, processing, manipulating, analyzing, and storing georeferenced data. These technologies have evolved over the years, with evolving technologies. Examples today, includes Geographic Information System (GIS), GPS, Remote Sensing, etc. For this paper, we shall zero in more on GIS. There is no single detailed and articulated history of what is known as GIS, because it evolved through multiple parallel, but separate applications across numerous disciplines (Pickles, 1999). Although there are multiple claims as to the exact origin, however, what is today known as GIS began about 1960, following the discovery that maps could be programmed using simple code and then stored in a computer allowing for future modification when necessary. GIS has evolved with the technologies through the years. From being deployed in mainframe computers, it evolved through the desktop GIS, to Web and Mobile Platforms (Sibe, 2009). The use of the Web as a dissemination medium for maps can be regarded as a major advancement in cartography and opened many new opportunities, such as real time maps, cheaper dissemination, more frequent and cheaper updates of data and software, personalized map content, distributed data sources and sharing of geographic information (Neumann, 2007). Today, interactive maps are served seamlessly through mobile phones.

The National Center of Geographic Information and Analysis (NCGIA) defines GIS as a system of hardware, software, and procedures to facilitate the management, manipulation, analysis, modeling, representation and display of georeferenced data to solve complex problems regarding planning and management of resource. It is a simplified, yet systematic way of representing geographic reality in a digital platform. Geospatial technologies have evolved from the static computer mapping of the 70's to Spatial Database Management in the 80's, Map Analysis/Modeling in the 90's and the web-based spatial solutions of today, allowing millions of ordinary users to take advantage of the technology to solve complex challenges (Ghosh et al, 2012). The proliferation of web-based solutions has opened a new vista of opportunity to a wide range of application areas and a seemingly unending audience. Governments across the world are leveraging these to offer smart governance (Sibe, 2014). A GIS can perform complicated analytical functions and then present the results visually as maps, tables or graphs, allowing decision-makers to virtually see the issues before them and then select the best course of action. The advent of GIS has broadened the application areas of mapping. GIS has changed from been just a tool for mapping physical geographic features to a tool that can map just about any feature - from physical to socioeconomic, as long as it can be tied to some geography. Another great feature of mapping applications is that it allows for different layers of information to be combined, analysed and studied in relation to each other. With 
GIS, trends could be revealed, patterns extracted and scenarios simulated (Sibe, 2010).

\section{GIS AND WASTE MANAGEMENT}

As cities grow, their waste challenges become more challenging. Thus, city Planners have continued to turn to technology, to improve their effectiveness. GIS is one of such technologies that have proved quite effective. GIS offers planners the ability to visualize the solid waste situations and facilitate route analysis through mapping (Shoba \& Rasappan, 2013). Waste data has a spatial component, therefore, GIS remains an important tool in planning and management.

Studies have shown that in developing countries, the major causes of solid waste management problems can be traced to poor linkages between spatial and non-spatial data components of the waste management process. The issues, such as inefficient waste collection, high operational costs, uncoordinated collection point, etc., can all be traced to the poor linkages (Kyessi \& Mwakalinga, 2009). GIS serves as the perfect solution to bridge these linkages. GIS has been deployed by decision makers in modeling, analyzing, and simulating various challenges relating to Solid Waste Management. It has been deployed successfully, for performing tasks such as, siting of communal receptacles, transfer stations and landfills, optimizing the collection and transportation, and local forecasting of waste. These spatial modeling tools have been key to collection and transport optimization, as well as boost overall efficiency of the entire waste management process (Kallel, et al., 2016).

\section{THE WASTE MANAGEMENT \\ CHALLENGE IN PORT HARCOURT}

The city of Port Harcourt has been contending with the challenges of management over the years. Solid Waste can be sighted along the major roads, with heaps of dumps lining some streets (Agwu, 2012). A drive through the city will reveal the heaps of solid waste lined up the roads especially at the approved dumping times of RIWAMA. Even the median strips are not spared, as residents have converted the medians as refuse receptacle points. Some of the reasons for this reckless dumping, include, insufficient litter bins and receptacles, poor awareness by the citizens, citizens indiscipline and irresponsibility, and inadequate refuse collection services. As a result of the littering many drains are blocked with water pollution becoming an imminent public health issue (Tamunobereton-ari et al., 2012).

In Rivers State, the Agency saddled with the responsibility of Waste Management is the Rivers State Waste Management Agency (RIWAMA). They have the responsibility of collecting wastes from receptacles and disposing same in designated dump sites. It was a creation of an Act of the Rivers State House of Assembly in 2017 and given the statutory responsibility of maintaining a clean environment (Obuah \& Okon, 2017). Currently, residents are expected to bag their wastes and drop them at designated receptacles, for onward pick up by RIWAMA Waste Contractors. Due to a myriad of challenges, this method has proved visibly inefficient and unsustainable.

Some of the challenges we observed before the take-off of the project, includes:

(1) Shortage of Waste Contractors

(2) Receptacles are not mapped or clearly marked. Thus, residents in most cases claim not to know the nearest receptacle. In most cases, receptacles were created "spontaneously" by citizens. Citizens clearly did not know the approved receptacles, as sustained illegal dumping of waste at a particular point, tends to "legitimize" the use as a receptacle over time.

(3) Zones were not mapped out based on volumes of wastes generated; they were identified based on convenience of collection. That is, there was no articulated map that clearly delineates the city to zones, for ease of planning and management.

(4) Citizens were detached from the waste management process. No framework for citizens engagement. No clear channels of communication.

(5) Since the Agency did not use technology, enforcement was through a Task Force approach; a method that is both inefficient and expensive.

(6) Lack of effective supervision and performance tracking of contractors.

(7) Citizens dumping outside of the prescribed timetable. Thus, in some case, they dump after the Waste Contractor had evacuated waste from the receptacle for that day.

(8) Operations, planning, and management was not scientific and precise

(9) Mode of refuse collection has remained cumbersome with workers manually loading refuse trucks rather than automated equipment.

(10) No tools for analytics, quite critical for strategic and contingency planning.

To address these challenges, RIWAMA commissioned ESense Technologies Ltd, an indigenous geospatial technology company, to develop a geospatial application to achieve the following:

(1) Geolocation of all Receptacles and Dumpsites

(2) Design a Portal that integrates the website and the mapping component. The geospatial portal should facilitate planning and management of the process.

(3) A Mobile App to stimulate citizen participation.

(4) Social Media Integration

\section{METHODOLOGY}

\subsection{User Needs Assessment and System Analysis}

The first task was to go through the processes with the staff of RIWAMA, to understand how things were done manually. Designated staff were interviewed to understand the current manual process. Contractors were also interviewed to understand things from their perspective. Also, citizens were randomly sampled to share their perspectives on the current challenges associated with the current system of waste management. Our design was shaped by our findings from this interaction.

\subsection{Field Data Collection}

Our Field staff visited the various receptacles and dump sites in the areas of coverage, consisting of Port Harcourt City LGA, Obio Akpor LGA, Oyigbo LGA and Eleme LGA. At each receptacle, our team, armed with a field notepad, a GPS and a Digital Camera, took pictures and GPS coordinates. They also noted the landmarks as well as nearest known address.

\subsection{Quality Control}

Data gotten from the field went through series of quality control to ensure integrity, precision, and spatial sense. The field data officer submited data entered to a quality control officer to evaluate for accuracy, precision, and integrity. Once 
data passes our quality control tests, they were harmonized and saved in the geospatial database.

\subsection{Mapping and Geospatial Analysis}

Maps were produced showing all the receptacles and dumpsites. Also, routes were mapped. Before this time, the road lengths were not accurately established; we achieved this easily, using GIS. This is quite important as the designated dumpsites were hitherto randomly chosen, without any scientific basis. Also, the zones were mapped out, for ease of administration. This was necessary for effective planning. The visualization capacity of GIS made this quite easy and interesting. ESRI ArcMap Software was used for the mapping process.

\subsection{Web Application Analysis}

At the time of this project, the Agency did not even have a functional website. Therefore, we had to create one that integrated the spatial components. Thus, once you got to the website, you could perform very complex geospatial analysis, without having sophisticated GIS knowledge. One of the key advantages of serving GIS on the web is that it allows people with less GIS sophistication, to perform complex GIS analysis and functions. To reduce cost, the application was deployed using opensource platform. Also, to drive down cost of data acquisition, we leveraged existing data, by building the application on the Google platform. This gave us access to quality datasets at almost no cost. By building on the Google platform, we also leveraged their huge popularity, to serve the application to more persons.

\subsection{Mobile Application Design \\ Mobile Application Design}

Nigeria has about 191 million active mobile lines (Nigerian Communications Commission, 2021). More and more Nigerians are surfing the web with their mobile phones. Thus, we had to leverage this impressive mobile tele-density to stimulate citizen participation in Waste Management. Thus, we designed a mobile application, using the most modern programming toolset on the Open-Source Platform. The Mobile Application was deployed on Android Playstore, so that members of the public can download for free.

\section{RESULTS}

Figures 1-5 shows some of the key functionalities of the RIWAMA geospatial application. The Web Application has the following functionalities:

(1) An admin module that allows you manage the portal. Using this function, the administrator can manage users and processes, post news items in real time, approve posts and respond to citizen-posts.

(2) Users can perform complex administrative and spatial analysis, without having sophisticated GIS functions.

(3) Upload spatial coordinates, pictures and other key attributes of receptacles and dumpsites.

(4) Search for nearest receptacle. This search will automatically spool out the results of the three closest waste facilities.

(5) Report any incidence, such as defaulting contractors or illegal receptacle. Citizens can quickly and easily report such incidences with detail, from their mobile phones. Such reports automatically pick the coordinates of the citizen, or allow user input the address manually. Pictures can also be attached to reports; this makes it quite graphic and accurate. When using a desktop or laptop, the application relies on the location component of your service provider.

(6) Administrator can register Contractors and Service Providers.

(7) View news feeds

(8) Perform complex analysis, such as tonnage analysis. This automatically computes the tones per zone, and outputs a graph. Please note that this will be done based on the information supplied.

(9) Functionality to toggle between the map view and the satellite imagery view.

Figures 6 and 7 shows screen shots of the RIWAMA Geospatial Mobile Application. The Mobile Application has the following key functionalities:

(1) View Maps - This defaults to your current location.

(2) Query Nearest Waste Facilities - This will spool the three nearest waste point on an interactive map.

(3) Query Facilities based on specified address.

(4) Report Incidences - Citizens can report incidences in real time. For example, citizens can report illegal dump sites or defaulting contractors.

(5) Sign-up/Sign-in as a vendor

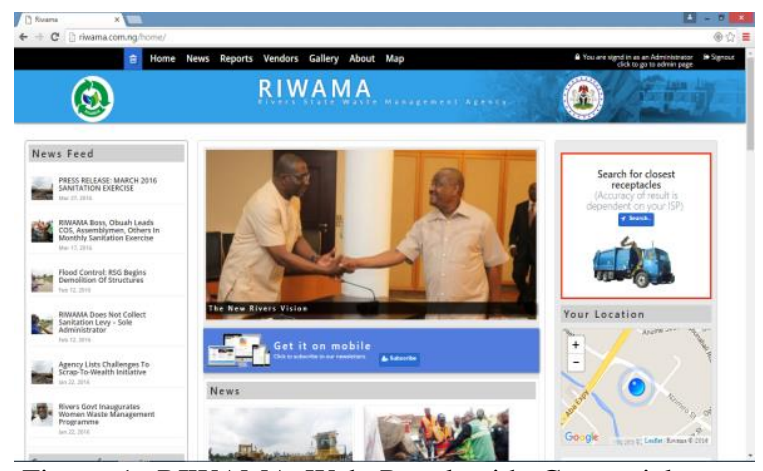

Figure 1. RIWAMA Web Portal with Geospatial Component

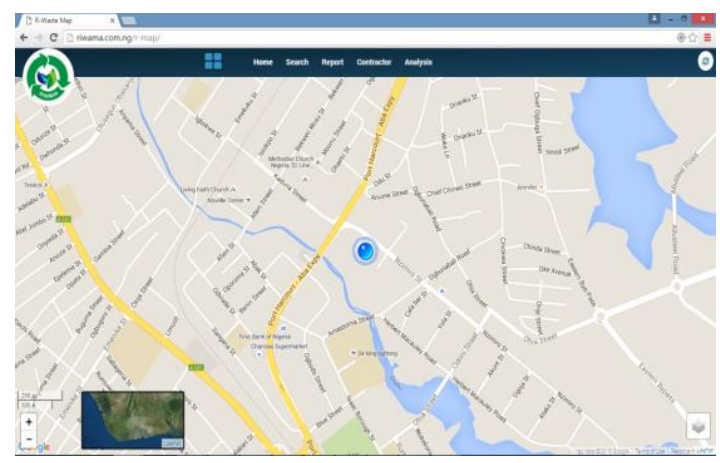

Figure 2. Web Component of Mapping Application 


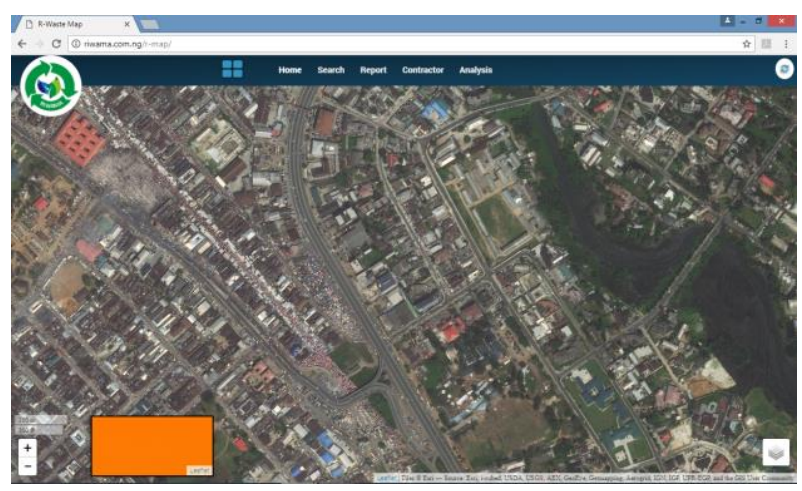

Figure 3. Web Mapping Application showing Satellite Imagery View

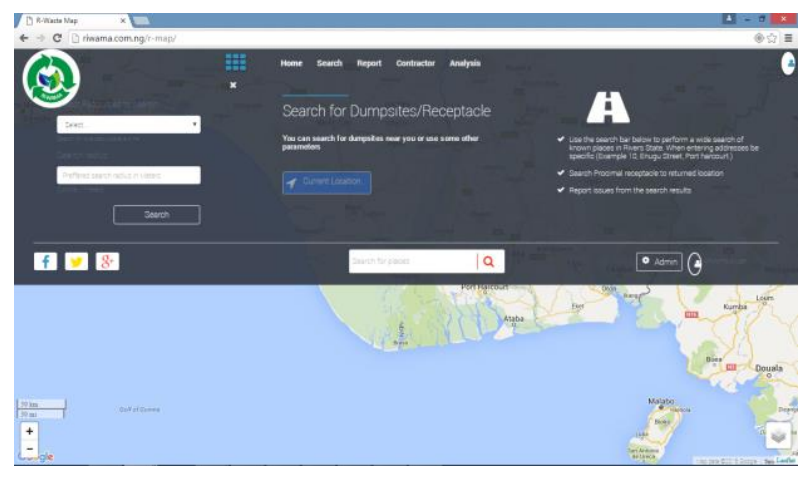

Figure 4. Web Mapping Application showing Search Tool

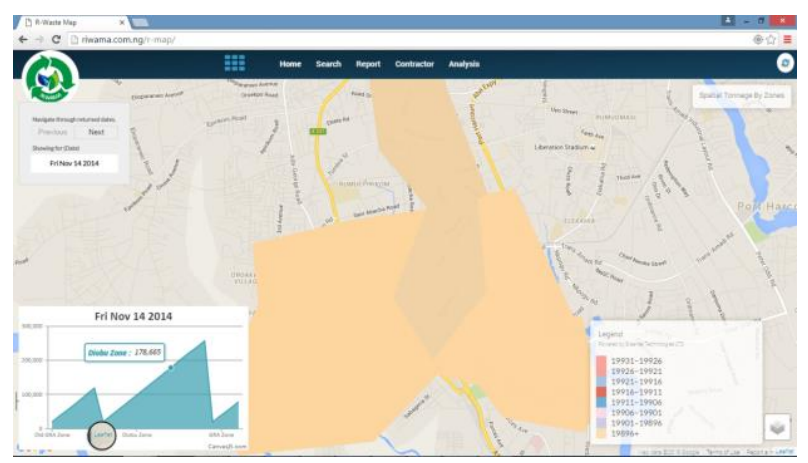

Figure 5. Web Mapping Application showing Solid Waste Tonnage Analysis

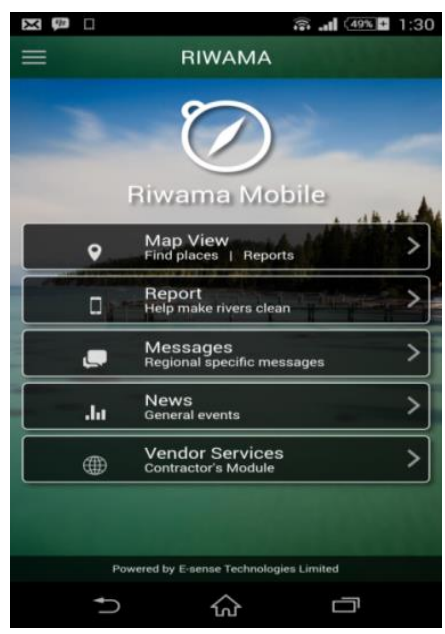

Figure 6. Home Screen of the RIWAMA Mobile Application
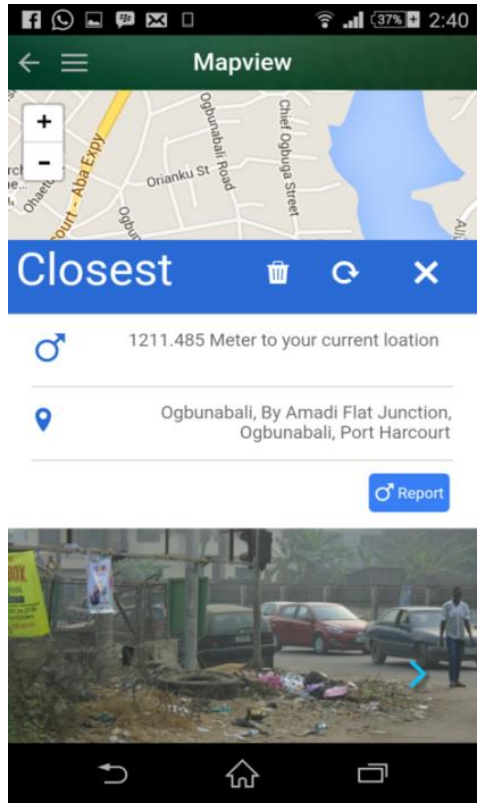

Figure 7. Search Result for Nearest Dumpsite

\section{CONCLUSION AND RECOMMENDATIONS}

The project was a huge success, especially considering the funding limitations. The application has automated most of the key back-end functions, bring precision in the planning process. One of the key challenges solved was the stimulation of citizen-participation in the waste management process. This solution allowed citizen to report incidences and defaulting contractors.

An ordinary user, with a working knowledge of Web browsers, or with an Android phone, could perform tasks hitherto restricted to the GIS user with sophisticated skills. This ensured that more and more users become "spatially aware" and location sensitive. Governments across the globe and especially in developing countries can leverage the potentials of low-cost Web-based GIS applications like this for planning and effective governance.

Below are some recommendations:

1. In Rivers State, Waste Management is still seen as a government service. That is clearly not sustainable. Waste Management is big business. To professionalize this sector, there should be more private sector participation. Government may continue to regulate, but the core of the services should be private sector driven. This will bring in more professionalism, and more investment to the sector.

2. Residents should be made to pay for waste management services as a part of utility services being rendered by the agency and the contractors. This will reduce or eliminate the overbearing control of government on the sector that should be largely private sector driven.

3. The current application focused more on stimulating citizen-participation. There's a proposed module to handle more tracking related functions for the Agency and Waste Contractors. This module would be key to performance monitoring and supervision, and it is highly recommended.

4. It is one thing to develop an application; it's another thing to maximize the application. The agency 
needs to do more to maximize usage and stimulate participation from citizens.

5. There is the human component in every system. Technology itself needs the human input. Where this is lacking, success will be dwarfed. For this to be a success, citizens would like to see responsiveness. For example, if citizens see timely response to their reports, they'll have more faith in the application.

6. There are other possible channels this can be deployed (Apple Store, Blackberry Store, etc). The application needs to be deployed on these other channels to serve more citizens.

7. Data is key to any successful GIS project. The accuracy and efficiency of the GIS application is hinged on the quality of the datasets. It is important that data should be updated more often than is currently done.

8. Waste Management is not just about collection and transportation. It goes beyond that to sorting, treatment, recycling, etc. This application only facilitates collection and decision support; the rest of the tasks will depend on the Agency's investment in other forms of technology, that will handle these.

9. Data Gathering was limited to 4 LGAs. We recommend that this be extended to cover the entire Rivers State.

10. People only get to use an app that they know exist and can solve their problems. The agency needs to do more to advertise this to citizens.

\section{ACKNOWLEDGMENTS}

Thanks to the Management of Rivers State Waste Management Agency (RIWAMA) and E-Sense Technologies Limited for the actualization of this project and for the contribution to this Paper.

\section{REFERENCES}

[1] Agwu, M.O. (2012). 'Issues and Challenges of Solid Waste Management Practices in Port Harcourt City, Nigeria- a behavioural perspective'. American Journal of Social and Management Sciences. https://pdfs.semanticscholar.org/9ee0/ded2c33732158db 1c0cec92b67b947a92ea7.pdf

[2] Collins H.W (2014). 'Residential Development Dynamics in Port Harcourt Metropolis: Implication for Efficient Urban Planning'. Journal of Environment and Earth Science, 4(6). www.iiste.org

[3] Elenwo, E.I. (2015). 'Solid Waste Management Practices in Port Harcourt Metropolis: Problems and Prospects'. Journal of Geographic Thought and Environmental Studies, $13(1)$. http://www.academix.ng/documents/papers/1504110900 4652.pdf

[4] Ghosh S., Raju P., Saibaba J. and Varadan G. (2012). CyberGIS and Crowdsourcing - A new approach in EGovernance.

http://www.geospatialworld.net/paper/application/Article View.aspx?aid $=24738$

[5] Kallel A., Serbaji, M.M. and Zairi, M. (2016). 'Using GIS-Based Tools for the Optimization of Solid Waste Collection and Transport: Case Study of Sfax City,
Tunisia'. Journal of Engineering, 2016 (2016). Available at: http://dx.doi.org/10.1155/2016/4596849

[6] Kyessi, A. and Mwakalinga, V. (2009), 'GIS Application in Coordinating Solid Waste Collection: The Case of Sinza Neighbourhood in Kinondoni Municipality, Dar es Salaam City, Tanzania'. FIG Working Week 2009: Surveyors Key Role in Accelerated Development https://www.fig.net/resources/proceedings/fig_proceedin gs/fig2009/papers/ts04b/ts04b_kyessi_mwakalinga_3219 .pdf

[7] Neumann, A. (2007). Encyclopedia of GIS, Springer, 2007. pg 1262

[8] Nigerian Communications Commission (2021). Subscriber statistics. https://www.ncc.gov.ng/statisticsreports/subscriber-data

[9] Nna, N.J. and Pabon, B.G. (2012). 'Population, Environment and Security in Port-Harcourt', IOSR Journal of Humanities and Social Science (JHSS), 2(1), PP 01-07. http://www.iosrjournals.org/iosrihss/papers/Vol2-issue1/A0210107.pdf?id=5633

[10] Pickles, J. (1999). Arguments, debates and dialogues: the GIS-social theory debate and the concern for alternatives. In: P.A. Longley, M.F. Goodchild, D.J. Maguire, and D.W. Rhind, ed., Geographical Information Systems: Principles, Techniques, Applications, and Management. New York: Wiley, pp. 49-60.

[11] Obuah, P.F and Okon, G.B. (2017). 'Environmental communication strategies of the Rivers State Waste Management Agency (RIWAMA): Implications for sustainable waste management in Nigeria'. 'International Journal of Development and Sustainability', 6(11), Pages 1541-1558. https://isdsnet.com/ijds-v6n11-4.pdf

[12] Shoba, B. and Rasappan, K. (2013). 'Application of GIS in Solid Waste Management for Coimbatore City'. International Journal of Scientific and Research Publications, 3(10). http://www.ijsrp.org/research-paper1013/ijsrp-p2231.pdf

[13] Sibe, R.T. (2009), Challenges of Mapping Applications in Health and Academic Research in the Underdeveloped World - Case Study of The Niger Delta Region (Nigeria). [Online] Geospatial World. https://www.geospatialworld.net/article/challenges-ofmapping-applications-in-health-and-academic-researchin-the-underdeveloped-world-case-study-of-the-nigerdelta-region-nigeria/

[14] Sibe, R.T. (2010), Web-Based Application for the Rivers State Government in Nigeria: Spatial Component for the e-Service Portal. [Online] Geospatial World. https://www.geospatialworld.net/article/web-based-gisapplication-for-the-rivers-state-government-in-nigeriaspatial-component-of-the-e-service-portal/

[15] Sibe, R.T. (2014). Geospatial Technologies and Smart Governance: Prospects and Challenges for Africa. In: Africa Geospatial Conference. India: Geospatial Media and Communications

[16] Tamunobereton-ari, I., mubo-Pepple, V. B. and Igbani, G. N (2012). 'Solid Waste Management Approach In Port Harcourt Municipality, Rivers State, Nigeria: The Effects On Public Health And The Environment'. Asian Journal of Science and Technology , 4(1), pp. 0405. 
International Journal of Science and Engineering Applications

Volume 11-Issue 01, 35 - 40, 2022, ISSN:- 2319 - 7560

DOI: $10.7753 /$ IJSEA1101.1006

http://www.journalajst.com/sites/default/files/Download \%201071.pdf

[17] Wizor, C.H. (2014). Residential Development Dynamics in Port Harcourt Metropolis: Implications for Efficient Urban Planning. Journal of Environment and Earth Science,

4(6).

http://www.iiste.org/Journals/index.php/JEES/article/vie $\underline{w} / 11851$ 